\title{
GCU
}

Glasgow Caledonian

University

University for the Common Good

\section{Help-seeking behavior in victims of elder abuse: a systematic review}

Fraga Dominguez, Silvia; Storey, Jennifer E.; Glorney, Emily

Published in:

Trauma, Violence, and Abuse

DOI:

$10.1177 / 1524838019860616$

Publication date:

2021

Document Version

Author accepted manuscript

Link to publication in ResearchOnline

Citation for published version (Harvard):

Fraga Dominguez, S, Storey, JE \& Glorney, E 2021, 'Help-seeking behavior in victims of elder abuse: a systematic review', Trauma, Violence, and Abuse, vol. 22, no. 3, pp. 466-480.

https://doi.org/10.1177/1524838019860616

\section{General rights}

Copyright and moral rights for the publications made accessible in the public portal are retained by the authors and/or other copyright owners and it is a condition of accessing publications that users recognise and abide by the legal requirements associated with these rights.

Take down policy

If you believe that this document breaches copyright please view our takedown policy at https://edshare.gcu.ac.uk/id/eprint/5179 for details of how to contact us. 
Help-seeking behavior in victims of elder abuse: A systematic review

Silvia Fraga Dominguez, Jennifer E. Storey, Emily Glorney

Royal Holloway, University of London

Author Note

The authors declare no conflict of interest. The first author has been supported by a college scholarship by the School of Law at Royal Holloway, University of London.

Correspondence concerning this article should be addressed to Jennifer E. Storey, School of Law Royal Holloway, University of London, Egham, Surrey TW20 0EX. Phone: 01784

414966, e-mail: Jennifer.storey@rhul.ac.uk 


\begin{abstract}
Elder abuse has become increasingly relevant for intervention and study in the context of an aging population. One of the major barriers to progress in the field is under-reporting of elder abuse by victims. This systematic literature review aimed to synthesize the available findings regarding victims' help-seeking behavior to inform practice, understand the limits of the evidence, and identify research gaps. A comprehensive search of published and unpublished literature was undertaken, and studies were included if they addressed help-seeking behavior from the perspective of elder abuse victims aged 60 and older. A total of 19 studies met inclusion criteria for review. Findings are presented as a narrative synthesis organized according to help-seeking barriers, facilitators, sources of help, the responses of others, and the characteristics of victims more likely to seek help. Although barriers and sources of help received detailed attention across all studies, findings regarding victim characteristics and facilitators for and responses to help-seeking were limited. The results suggest that there are many barriers to help-seeking, and that some victims only seek help when the abuse is perceived as unbearable or they fear for their safety. Results are discussed in relation to implications for intervention, including suggestions to enhance help-seeking behavior. Future research should identify facilitators of help-seeking among victims of elder abuse and victim characteristics associated with early disclosure. Research efforts should frame help-seeking as a continuing process, and study ways in which the responses of others may impact future help-seeking or service engagement.
\end{abstract}

Key words: elder mistreatment, elder neglect, help-seeking, disclosure, facilitators, barriers. 
Help-seeking Behavior in Victims of Elder Abuse: A Systematic Review

Within the context of an aging global population, the phenomenon of abuse and neglect of older people is in increasingly urgent need of study (United Nations, 2017). First addressed in the 1970s as 'granny-battering' (Burston, 1975), there are still current challenges to developing a single definition. These include differing cultural perceptions of abusive behaviors, and differing opinions across researchers, practitioners and older persons (Enguidanos, Deliema, Aguilar, Lambrinos, \& Wilber, 2014; Killick, Taylor, Begley, Anand, \& O’Brien, 2015). Despite disagreements, elder abuse can be defined as “a single or repeated act or lack of appropriate action, occurring within any relationship where there is an expectation of trust, which causes harm or distress to an older person” (WHO, 2018, para. 2). Similarly, Centers for Disease Control and Prevention define elder abuse as “an intentional act, or failure to act, by a caregiver or another person in a relationship involving an expectation of trust that causes or creates a risk of harm to an older adult” (CDC, 2018, para. 1).

Elder abuse is a phenomenon without borders, occurring across countries and cultures, which severely affects its victims (Yunus, Hairi, \& Choo, 2017). Despite this, elder abuse lacks the attention received by abusive behavior toward other age-related groups such as children or violence perpetrated in an intimate relationships (Daly, Merchant, \& Jogerst, 2011; Dyer, Connolly, \& McFeeley, 2003; Erlingsson, 2007). Much of the research on elder abuse originates from the United States (U.S.) and a considerable proportion has focused on obtaining prevalence estimates in different countries and identifying risk factors (Erlingsson, 2007; Pillemer, Burnes, Riffin, \& Lachs, 2016). Prevalence estimates often vary greatly between studies because of different methodologies, definitions, age cut-offs, and populations. However, a systematic review highlighted the significance of the problem, with prevalence rates of elder abuse ranging between $3.2 \%$ and $27.5 \%$ in general population 
studies (Cooper, Selwood, \& Livingston, 2008). Although elder abuse can take many forms, those most commonly considered in research are financial abuse or exploitation, neglect, and physical, psychological or emotional, and sexual abuse, sometimes with co-occurrence known as poly-victimization (Heisler, 2017; Lachs \& Pillemer, 2015).

Among the published elder abuse research, there is recognition that disclosure rates and formal reports of victimization are low (Bergeron \& Gray, 2003; Killick \& Taylor, 2009). As a result, it is estimated only a small proportion of cases are known to formal services (Cooper et al., 2008; O'Keeffe et al., 2007). This suggests not only that the prevalence rates might be underestimated but, also, that assisting victims is a challenge. Indeed, major barriers to assisting elder abuse victims are underreporting, victims’ rejection of intervention, and lack of service utilization (Barker \& Himchak, 2006; Naughton, Drennan, Lyons, \& Lafferty, 2013). These factors are critical to address not least because when abuse remains hidden there is a potential for escalation (Storey \& Perka, 2018).

Due to elder abuse being perpetrated primarily behind closed doors and by family members (Jackson, 2016), there is an assumption that victims face many obstacles when disclosing elder abuse. However, much of the evidence is anecdotal or has not been gathered from victims themselves, and knowledge of barriers to help-seeking is limited. Research on barriers to help-seeking for elder abuse has mostly used samples of older adults from the general population who had not been victimized, vignette methodologies, or focus group discussions (Chokkanathan, Natarajan, \& Mohanty, 2014; Gibson, 2013). Others have focused on a specific cultural minority residing in the U.S. (e.g., Lee, Moon, \& Gomez, 2014). Understanding victims’ perspectives of elder abuse is essential to addressing underreporting but knowledge in this area is limited and lacks specificity. 
The understanding that victims are unlikely to disclose has resulted in policies to increase professional detection of warning signs, and on developing mandatory reporting statutes to protect victims (Barber, 2008; Gibson, 2013). Professional training to front line staff can support the identification and reporting of elder abuse, and there are over 15 available tools to screen and assess elder abuse (Spencer, 2009). Although increasing professional reporting is necessary, this has led to a lack of focus on the victims' perspective, and fails to acknowledge the many victims who may not display identifiable signs of abuse or be in contact with professionals due to isolation-a risk factor for elder abuse (Lachs \& Pillemer, 2015). Unfortunately, this practice is consistent with general research trends that neglect the views of older people (Burnes, Lachs, Burnette, \& Pillemer, 2017; Erlingsson, 2007; Killick et al., 2015; Mysyuk, Westendorp, \& Lindenberg, 2016). Although some victims will not be able to disclose abuse because of physical or cognitive barriers, a considerable number of older people could do so, and thus research should focus on identifying and understanding methods of increasing victims’ help-seeking (Barber, 2008; Brank, Wylie, \& Hamm, 2011).

\section{The Present Study}

This systematic literature review aimed to provide a synthesis of the published and unpublished research on elder abuse victims’ help-seeking behavior to inform practitioners and guide future research efforts. To the best of the authors' knowledge, there is no published review on help-seeking behavior among elder abuse victims. Before any further research is conducted, it would be prudent to identify the common themes in the literature, limitations of studies, and any gaps in the topics covered. The main areas of interest for this systematic literature review are help-seeking barriers, facilitators, common sources of help-seeking, the outcomes or responses to seeking help, and the characteristics of victims who are more likely to seek help. 
The primary question that this systematic review will answer is: What are the characteristics of help-seeking behavior among victims of elder abuse?

Specifically, the review will address:

1. What are the barriers that prevent help-seeking among victims of elder abuse?

2. Are there any abuse characteristics associated with increased barriers to help-seeking?

3. What are the facilitators of help-seeking behavior among victims of elder abuse?

4. Are there any abuse characteristics associated with increased help-seeking behavior?

5. From whom do victims of elder abuse seek help?

6. What are the responses of third parties to elder abuse victims' help-seeking and how do they influence further attempts to seek help?

7. What characterizes victims who are more likely to seek help?

\section{Method}

\section{Definition Parameters}

Due to inconsistency of definition in the field and the lack of specificity of some studies when addressing elder abuse, an inclusive approach was adopted. Although the most commonly accepted definition specifies that elder abuse be perpetrated by someone the victim knows and trusts, because of the scarcity of research with elder abuse victims, studies that included analysis of both stranger and known perpetrator abuse were incorporated. Studies that examined help-seeking behavior exclusively as a result of stranger victimization were outside the scope of this review. The context of stranger or known abuse perpetrator is made explicit in the discussion of the results of this review.

The age cut-off that defines an elderly person is also a source of disagreement in the literature (Addington, 2013; Bows, 2018). For the purposes of this systematic review, a conservative age cut-off of 60 years was used, in concordance with that used by the World 
Health Organization (e.g., WHO, 2018). Lower age cut-offs were considered if the use of such a cut-off was justified within the articles reviewed on the basis of cultural differences or lower life expectancy (e.g., Indigenous population in Australia; Dow, Gaffy, \& Hwang, 2018); however, no relevant studies with such justifications were identified.

Within this review, help-seeking behavior was broadly understood as informal or formal disclosure of elder abuse victimization, also referred to as 'reporting' (e.g., Jackson \& Hafemeister, 2015). Studies involving elder abuse victims in which help-seeking for the abuse was not a primary focus were excluded (e.g., examination of the degree to which a service, such as Meals on Wheels, was utilized by victims; Barker \& Himchak, 2006). Helpseeking or disclosure had to be conceptualized as resulting from the abusive situation (e.g., talking to a family member or professional about the mistreatment or filing a report). The self-report of abuse to researchers in the context of a prevalence study was not considered as help-seeking. Further, studies were excluded if they only provided figures on the prevalence of self-reported abuse within a sample of victims without any further discussion of helpseeking. Where possible, findings highlight differences between informal and formal disclosure to account for the possibility of differences between these two modes of disclosure, which have been found in samples of intimate partner violence victims (Sylaska \& Edwards, 2014).

\section{Search Process}

The approach was informed by the Preferred Reporting Items for Systematic reviews and Meta-analyses (PRISMA) Statement (Moher, Liberati, Tetzlaff, \& Altman, 2009). The protocol for this systematic literature review was registered on PROSPERO -International prospective register of systematic reviews- (Booth et al., 2011; REGISTRATION NUMBER MASKED FOR PEER-REVIEW). 
A comprehensive search of several bibliographic databases relevant to the field of elder abuse was conducted to identify published and unpublished research, specifically: PubMed (via NCBI), PsychINFO (via EBSCOHOST), Scopus (via Elsevier), Web of Science (via Clarivate Analytics) and ProQuest Dissertations \& Theses Global (via Proquest). Articles utilized in the review included all articles available in the databases up to and including July $5^{\text {th }}, 2018$, when the final searches were conducted. Search terms included those referring to the phenomenon of elder abuse (i.e., elder mistreatment, elder neglect, mistreatment of older adults) and those used to describe help-seeking behavior (i.e., help-seeking, disclosure, reporting). To broaden the search, several terms were truncated, e.g., disclos*. The search term relating to disclosure was limited to the title/abstract in all databases to prevent the retrieval of irrelevant articles (e.g., many articles include disclosure statements).

Grey literature such as dissertations and conference proceedings were targeted by the search on ProQuest Dissertations and Theses Global and Web of Science, respectively. With the aim of identifying further "grey" literature additional searches in Google Scholar, the OpenGrey repository, the Grey Literature Report database, and the World Health Organization Institutional Repository (IRIS) were conducted. To narrow the results obtained through Google Scholar, all possible combinations of the key search terms were added to the Advanced Search option restricting the terms to the title. In addition to these databases, the websites of several organizations working with elderly clients were searched, via their resources/publications section, in both English and Spanish languages (e.g., AgeUK in the United Kingdom, Senior Rights Victoria in Australia).

Searches identified 2,037 published and unpublished sources. After removal of duplicates using referencing software, 1,388 articles remained for screening. The search process is illustrated in Figure 1. 


\section{Inclusion and Exclusion Criteria}

Titles and abstracts of the 1,388 sources retrieved were screened against inclusion criteria:

- Original empirical published or unpublished research data relating to victim-focused help-seeking behaviors in the context of elder abuse, regardless of the specific definition used.

- Research focusing on victims aged 60 and older, unless a rationale was provided for a lower age cut-off (e.g., cultural differences, lower life expectancy).

- Articles in English or Spanish language.

Titles and abstracts of the retrieved sources were compared to the inclusion criteria and 1,242 were eliminated. Full texts of the remaining articles $(n=146)$ were reviewed against the following exclusion criteria:

- Addressed reporting from the perspective of professionals who suspect or are aware of elder abuse cases.

- Conducted solely with non-victim populations.

- Conducted with victim and non-victim populations that failed to present the results for victims separately.

- Conducted with an age cut-off below 60 (without justification based on culture or life expectancy) that failed to present the results for the older victims separately.

- Not original research (e.g., opinion papers, book reviews).

- Failed to address help-seeking or disclosure in any detail.

Citations and reference lists of the remaining 17 articles were reviewed in detail yielding two additional sources for a final sample of 19 .

\section{Quality Assessment}


Two quality assessment tools were utilized: one for qualitative and one for quantitative studies. The objective of the quality assessment was not to exclude low quality studies, but to evaluate the quality of the available research on the topic to inform future research and the interpretation of the findings. For qualitative and mixed method studies, the Critical Appraisal Skills Program was used (CASP) (2018) (https://casp-uk.net/casp-toolschecklists/), which provides a 10-question checklist that helps to systematically appraise a qualitative piece of research. For the quantitative studies, an adaption of the National Institutes of Health (NIH) tool for cohort, observational, and cross-sectional studies was employed (National Institutes of Health, 2016). From the original 14 questions (https://www.nhlbi.nih.gov/health-topics/study-quality-assessment-tools), the adaptation (see appendix) excluded questions $6,7,10$, and 13 on the basis that they were irrelevant to the identified studies, which were cross-sectional in nature and lacked a temporal dimension in their measurement. Further, question 12 was omitted because it was not relevant to the quality of the studies reviewed. For the remaining nine questions, exposure variables were defined as the assessment of elder abuse victimization (in descriptive studies) and/or the assessment of other independent variables in relation to help-seeking (outcome or dependent variable).

\section{Results Extraction}

Data were extracted based on the aims of the review to identify: (a) barriers to, (b) facilitators and (c) sources of help-seeking behavior among victims of elder abuse; (d) responses of others to victims' help-seeking behavior; and e) characteristics of victims more likely to seek help. Similarly, special attention was paid to the methodology and sampling of the studies to identify trends and gaps that could inform future research. When a study presented results on other topics without relating them to the focus of this review (e.g., the consequences of abuse; barriers regarding access to services from the perspective of 
professionals), only the results relevant to the review were extracted. Thematic analysis was conducted to inductively explore common themes across the studies organized by the four first areas of interest (Braun \& Clarke, 2006). Results regarding the characteristics of victims who are more likely to seek help are presented separately as both the quality and quantity of these data did not warrant thematic analysis. Quantitative content analysis was used to ascertain frequencies of the specific group of barriers mentioned across studies (Elo \& Kyngäs, 2008).

\section{Results}

\section{Quality Assessment}

The results of the quality assessment of quantitative and qualitative studies can be found in Tables 1 and 2, respectively. In general, quantitative studies adequately outlined a research question, population and selection of participants, and measurement of outcome and exposure variables. However, all studies failed to provide an adequate sample size justification, and two failed to report the participation rate. Overall, most qualitative studies included the different components assessed by the CASP tool. The most common aspect that studies failed to address was the relationship between the researcher and participants in both the formulation of research questions and the data collection process.

\section{Overview of the Studies}

An overview of the studies included in the review can be found in Table 3. Among the 19 sources included, 10 were qualitative (or mixed-methodology) and 9 were quantitative. Sample sizes (excluding non-victim participants) ranged from six (Chokkanathan et al., 2014) to 457 participants (Tamutiene et al., 2013). In most studies, information was obtained directly or indirectly from victims $(n=17)$. However, two studies included participants who were professionals reporting on their experience working with elder abuse victims (Bows, 2018; Wydall \& Zerk, 2017) and one of the studies with victim participants also included 
Adult Protective Service workers and third-party adults (Jackson \& Hafemeister, 2015). Conceptualizations of abuse varied, but most focused on abuse by a known and trusted person. However, four studies explicitly included, or did not exclude, stranger abuse (Acierno et al., 2018; Bows, 2018; Mowlam, Tennant, Dixon, \& McCreadie, 2007; Naughton et al., 2013). Many studies did not specify their conceptualization of help-seeking, but those that did generally framed it as informal or formal disclosure to others or taking action to change the situation or prevent the reoccurrence of the abuse. In some cases, help-seeking focused exclusively on reporting to the police or other authority (e.g., Acierno et al., 2018). In addition, a study focused on reporting or talking to somebody about the most serious incident of abuse (Tamutiene et al., 2013). Studies typically set an age cut-off of 60 or 65 years, with a cut-off of 66 years in O’Keeffe et al. (2007). Studies spanned 15 different countries (one study included data from five different countries; Tamutiene et al., 2013). The two most common countries were the United Kingdom (UK) $(n=4)$ and the U.S. $(n=3)$.

Many of the quantitative studies were descriptive, often part of a broader project that focused on prevalence, and asked victims whether they had sought help, queried the sources of help, or asked about the reasons for not seeking help. A minority of the quantitative studies involved an analytic component and tried to identify the association between certain variables and help-seeking (e.g., Naughton et al., 2013). Qualitative studies usually aimed to understand the experience of elder abuse from the perspective of already identified victims (or professionals working with victims) and the method was most often an in-depth interview.

Rates of help-seeking were reported in 10 studies. For abuse committed by a person known to the victim, help-seeking behavior was engaged in by $11.1 \%$ (Acierno et al., 2018) to $70 \%$ (O’Keeffe et al., 2007) of identified victims. The variability in findings may be explained by the definition used for help-seeking since the former study conceptualized it as reporting to the police/other authorities, whereas the latter considered individuals who had 
“sought help or advice from anyone” about the abuse (p. 127). Rates of help-seeking also varied by the type of elder abuse and the country examined (Tamutiene et al., 2013).

\section{Barriers to Help-seeking}

Barriers to help-seeking were reported in 14 studies, arising from either specific questions posed by the researchers, or as part of in-depth interviews regarding the victim's experience. Due to difficulties in comparing barriers across studies (different sample sizes, some studies offering options a priori and some coding inductively), barriers are presented according to themes. These themes are introduced in the order in which they were most commonly mentioned in the studies analyzed (i.e. a quantitative content analytic approach informs the prioritization of presentation of inductive thematic analysis themes).

Fear of consequences for self or the perpetrator in seeking help was mentioned in 12 studies, and it related to the dimensions of self and the perpetrator of the abuse. For example, victims were afraid of being institutionalized, of retaliation or worsening of the abuse, and of becoming abandoned, isolated, or ostracized by their communities (Acierno et al., 2018; Chokkanathan et al., 2014; Gil, Santos, \& Kislaya, 2017; Mowlam et al., 2007; Mysyuk et al., 2016; Ribot et al., 2015; Tamutiene et al., 2013). Despite the fear of retaliation, only Chokkanathan et al. (2014) reported specific threats made by the perpetrator to prevent victims from disclosing the abuse. In addition, victims mentioned the fear of harming the perpetrator or losing or worsening their relationship with them; this was sometimes paired with a desire to protect and help the perpetrator (Acierno et al., 2018; Chokkanathan et al., 2014; Jackson \& Hafemeister, 2015; Mowlam et al., 2007; Mysyuk et al., 2016; Souto, Merighi, Guruge, \& Jesus, 2015; Tamutiene et al., 2013; Vrantsidis, Dow, Joosten, Walmsley, \& Blakey, 2016). Other fears included “making a fuss” (Mowlam et al., 2007, p.35), being blamed, a general fear of authorities, and the fear of others knowing what was happening to them (Acierno et al., 2018; Lafferty, Treacy, \& Fealy, 2013; Yan, 2015). 
Individual feelings and external circumstances were perceived to make helpseeking more difficult $(n=11)$. Victims mentioned shame and embarrassment, self-blame, low self-confidence and self-esteem, physical frailty, socioeconomic dependency, the stigma associated with seeking help, and feelings of ambivalence (Acierno et al., 2018; Bows, 2018; Chokkanathan et al., 2014; Gil et al., 2017; Lafferty et al., 2013; Mowlam et al., 2007; Mysyuk et al., 2013; Ribot et al., 2015; Tamutiene et al., 2013; Vrantsidis et al., 2016). Some victims also alluded to anxiety and mentioned bereavement as a barrier to action (Bows, 2018; Mowlam et al., 2007). Other barriers included feelings of helplessness and that the abuse was beyond their control (Mysyuk et al., 2016; Yan, 2015).

Knowledge about services and their adequacy was a common barrier $(n=10)$. Victims reported a lack of knowledge regarding where to seek help (Acierno et al., 2018; Bows, 2018; Chokkanathan et al., 2014; Gil et al., 2017; Lafferty et al., 2013; Mowlam et al., 2007; Ribot et al., 2015; Yan, 2015), doubts about the capacity and adequacy of services to help them, a lack of trust in professionals, and accessibility barriers (Bows, 2018; Chokkanathan et al., 2014; Lafferty et al., 2013; Mowlam et al., 2007; Tamutiene et al., 2013; Wydall \& Zerk, 2017).

Family barriers were situated in the context of abuse perpetrated by relatives $(n=8)$. Victims associated seeking help with negative consequences for their family and placed emphasis on their relationship with the perpetrator and other relatives. In addition, some victims alluded to the perpetrators' dependency on them and their parental duty (in the case of adult-child perpetrators; Chokkanathan et al., 2014; Gil et al., 2017; Jackson \& Hafemeister, 2015; Mowlam et al., 2007; Mysyuk et al., 2016; Vrantsidis et al., 2016; Wydall \& Zerk, 2017; Yan, 2015). 
Characteristics of social networks, across family and community, were identified in six studies. Victims reported a general lack of effective social support, isolation, and in some instances that their only relationship was with the perpetrator (Chokkanathan et al., 2014; Jackson \& Hafemeister, 2015; Yan, 2015). Victims also anticipated denunciation by their communities and disbelief by others if they disclosed, and some believed that people they knew could not help them (Chokkanathan et al., 2014; Mysyuk et al., 2016; Tamutiene et al., 2013; Wydall \& Zerk, 2017; Yan, 2015).

Perception of abuse, although infrequently mentioned $(n=5)$, was understood as a barrier. There was some lack of awareness that abuse was occurring, difficulties labeling abusive behavior as such, and its perception as not serious enough to disclose (Gil et al., 2017; Jackson \& Hafemeister, 2015; Lafferty et al., 2013; Mowlam et al., 2007; Tamutiene et al., 2013). In contrast to this, Naughton et al. (2013) found that awareness of the term elder abuse was not associated with disclosure.

Cultural, generational or religious beliefs influenced disclosure and a desire to remain in their homes and communities and secure privacy ( $n=5$; Bows, 2018; Chokkanathan et al., 2014; Souto et al., 2015; Wydall \& Zerk, 2017; Yan, 2015). In an Australian study, Vrantsidis et al. (2016) reported that a sense of parental obligation was particularly strong among participants from Culturally and Linguistically Diverse backgrounds.

Characteristics associated with increased barriers to help-seeking rates included emotional/psychological abuse and neglect (Amstadter et al., 2011; Markovik, Peshevska, Sethi, Kisman, \& Serafimovska., 2014; Naughton et al., 2013). Specific barriers may arise when seeking help for abuse perpetrated by close family members (e.g., descendants, spouses/partners), as help-seeking is less common for this abuse compared to that perpetrated 
by other relatives, a neighbor, or by a paid home-help/caregiver (Gil et al., 2017; Tamutiene et al., 2013). Barriers to reporting also differed by perpetrator identity where "not wanting to get the perpetrator in trouble” (p. 6) was a more common barrier against reporting family, friends, and acquaintances compared to strangers (Acierno et al., 2018). Time to reporting increased when the perpetrator was a close family member (Mysyuk et al., 2016). This was in agreement with the finding of Jackson and Hafemeister (2015) that the time between detection or awareness of the abuse and reporting to authorities depends on the nature and quality of the relationship between the victim and perpetrator. Finally, in most cases of polyvictimization, victims cited a lack of information (98.4\%) or shame (94.3\%) as barriers in reporting (Gil et al., 2017).

\section{Facilitators of Help-seeking}

Facilitators of help seeking were reported in only six of the studies reviewed and included having a good network (both formally and informally), a lack of emotional attachment to the perpetrator, and a feeling of betrayal by a trusted person (Jackson \& Hafemeister, 2015; Mowlam et al., 2007; Vrantsidis et al., 2016). Most commonly, however, studies addressed the circumstances that led victims to seek help, such as when they perceived the abusive situation was critical in terms of intensity, seriousness, or frequency, and/or when they feared for their immediate personal safety or that of the perpetrator (Jackson \& Hafemeister, 2015; Mowlam et al., 2007; Mysyuk et al., 2016; Tamutiene et al., 2013; Vrantsidis et al., 2016; Yan, 2015).

\section{Characteristics associated with increased help-seeking behavior included financial} abuse being easier to talk about because it is more publicly discussed and experienced by others, making it less shameful to seek help (Mysyuk et al., 2016). This is consistent with the findings of Acierno et al. (2018), who compared perpetrator identity (family/friends/acquaintances vs. strangers) with reporting rates to authorities and found that 
financial abuse (but not emotional abuse) was more likely to be reported if perpetrated by a stranger. In connection to the impact of abuse, Tamutiene et al. (2013) found that several of the consequences of elder abuse (anger, depression, tension, sleeping difficulties, concentration difficulties, difficulties in relation with others) correlated positively with seeking help, although the type of analysis used does not allow inference of causality.

\section{Source of Help-seeking}

The sources from which victims sought help $(n=10)$ included formal and informal sources. Formal sources of help included health professionals (GP practice, community nurses), specialized services (domestic violence centers, specialist support groups), social workers, legal professionals (solicitors, prosecutors), the police, voluntary services, and local councils (Comijs, Pot, Smit, Bouter, \& Jonker, 1998; Gil et al., 2017; Lafferty et al., 2013; Mysyuk et al., 2016; Naughton et al., 2013; O’Keeffe et al., 2007; Souto et al., 2015; Yan, 2015). Informal sources included relatives, friends, and neighbors (Comijs et al., 1998; Lafferty et al., 2013; Mysyuk et al., 2016; Naughton et al., 2013; O’Keeffe et al., 2007; Ribot et al., 2015; Souto et al., 2015).

Naughton et al. (2013) and Tamutiene et al. (2013) found that victims generally favored contacting informal over formal sources, though there were variations between countries. Mysyuk and colleagues (2016) stated that informal help was sought when victims experienced psychological abuse and neglect and when perpetrators were family members, and formal help was sought in poly-victimization cases. In terms of specific sources of professional help, seeking help from the police was identified as a "last resort" for perceived experience of serious abuse (both Souto et al., 2015, p. 48; and Yan, 2015, p. 2700). Other studies indicated that each victim often seeks help from different sources (Mowlam et al., 2007; Vrantsidis et al., 2016). When victims did not seek help from external sources, some stated they dealt with the abuse themselves (Gil et al., 2017; Mysyuk et al., 2016; Tamutiene 
et al., 2013). For victims who sought help, Mysyuk and colleagues (2016) reported they had endured abuse for a period ranging from a couple of weeks to 6-7 months.

\section{Responses to Help-seeking}

Responses to help-seeking were reported in six studies and reflected mostly the degree of success in stopping the abuse or improving the victim's situation; there was little reported on the specific responses that victims obtained from third parties. Some victims were successful in seeking help, but others' attempts were unsuccessful or had mixed results (Comijs et al., 1998; Naughton et al., 2013; Souto et al., 2015). In one study, victims highlighted that the responses of others helped them to realize that abuse was taking place, and informal sources were mentioned as a bridge to formal resources (Lafferty et al., 2013). A positive response was obtained from both family and statutory services by many victims, and some victims found reporting helpful (Lafferty et al., 2013; Tamutiene et al., 2013). Other responses to victims were negative-for example, when frontline workers were unaware of how to help victims, or when neighbors were aware but did not want to be involved-and this lack of success resulted in feelings of hopelessness among victims (Souto et al., 2015; Yan, 2015). This finding is of critical importance given that other studies have found that several attempts to report or seek help may be required before victims receive help or decide to pursue the help that is offered (Mowlam et al., 2007; Vrantsidis et al., 2016).

Victim characteristics that were associated with seeking help included (Gil et al., 2017; Naughton et al., 2013):

- Poor mental health-related quality of life.

- Being in the younger (60-69 years) and older (80+ years) age groups.

- Being separated or divorced. 
In addition, Amstadter et al. (2011) reported that women were more likely than men to report emotional and physical abuse, whereas men were more likely to report sexual abuse, although no statistical analyses were provided. Tamutiene et al. (2013) found no significant differences in relation to age, marital status, education, income, or subjective evaluation of health status or quality of life.

\section{Discussion}

This systematic review synthesized empirical findings regarding elder abuse victims’ help-seeking behavior. The results indicate that victims face barriers to help-seeking across multiple contexts (internal, external, socio-cultural, systemic) and seek help out of fear for their personal safety or because social networks facilitate the disclosure and help-seeking processes. Victims disclose abuse experiences to formal and informal sources and receive both validating and dismissive responses. Similarly, they perceive and experience both positive and negative outcomes from their help-seeking efforts. Psychological abuse, neglect, and abuse perpetrated by family members are particularly difficult to report, and there are victims who decide not to seek help. When victims seek help, this is not always immediate, and they sometimes require several attempts to pursue any help offered. The evidence reviewed is limited because of study variation in terms of help-seeking conceptualizations and elder abuse definitions, types of abuse experienced, and due to the use of self-report and studies’ cross-sectional nature; thus, the interpretation of results warrants caution.

\section{Implications for Practice and Policy}

Awareness of elder abuse could be improved among older people, professionals, and the general population. Despite efforts to raise awareness through campaigns (Naughton et al., 2013) some victims remain uninformed of what elder abuse is, and lack knowledge about the services they can access. Awareness campaigns that rely on the attendance of older people to community centers and similar settings might miss those most at risk, and should 
employ methods most likely to reach and resonate with older adults (Krug, Dahlberg, Mercy, Zwi, \& Lozano, 2002). There should be a continued effort to extend the information about elder abuse to the general population because victims seek help from informal sources and might do so before contacting formal services (Lafferty et al., 2013),. A good example of a wide-reaching way of increasing awareness is the Friends Against Scams initiative (https://www.friendsagainstscams.org.uk/) by the National Trading Standards Scams Team (Baxter, Gordon, \& Salmon, 2017), which provides information about protection from scams and encourages recipients to share this knowledge with others within their communities and social networks. The effectiveness of this type of initiative could be tested in the context of awareness for abuse perpetrated by persons known to the victim.

Awareness amongst professional services could also be enhanced to ensure that, should victims disclose abuse, it is responded to in a helpful and positive manner that facilitates further help-seeking behavior. Findings revealed that good social support networks and positive relationships with professionals facilitated help-seeking and that a lack of trust in professionals and the impression that help was inadequate were barriers to help-seeking (Jackson \& Hafemeister, 2015; Yan, 2015). To assist professionals, who are often overburdened, training should be provided on how to adequately support and refer victims, and be directed to pay increased attention to cases where the older person lacks other social support (Jackson \& Hafemeister, 2015). Increased training and available solutions should help in creating spaces where victims are more likely to disclose concerns and where professionals feel supported to respond.

Professionals who suspect elder abuse will need to be ready to explore the many barriers that victims may face, particularly victims' fears regarding the consequences of disclosure and their attitudes towards services. Although some of the barriers will be more difficult to address and modify positively (e.g. fear of a negative reaction by the perpetrator 
or the community), others such as the lack of knowledge about services are more likely to be modified. One method to achieve professional awareness is through the use of a barriers checklist, proposed by Chokkanathan et al. (2014, p.74) for professionals in their work with older people, with the aim of ensuring continued service engagement. This type of checklist could also inform mandatory reporting training for professionals (where appropriate, given legal requirements) so that not only are risk factors for abuse and the detection of abuse emphasized, but also knowledge regarding the reasons why, or the situations in which, victims might attempt to hide the abuse.

Policies should aim to create environments where victims feel safe to disclose abuse without fear of consequences. This could be achieved by implementing victim-centered interventions that are based on an assessment of the clients' needs and wishes, including the exploration and limiting of interventions that a victim perceives as negative to encourage engagement with services. This is the course of action of services like the Elder Abuse Resource and Support Team in Canada, where the senior's wishes are a priority during the assessment and management of cases (Storey \& Perka, 2018). For example, victims might not seek help if doing so will lead to moving away from their communities and becoming isolated, or if they perceive the outcome of intervention to be worse than the abuse they are enduring (Enguidanos et al., 2014; Wydall \& Zerk, 2017). Special attention should be paid to cases in which the perpetrator is a descendant of the victim, as the results of this review suggest that these are complex cases in which victims might want to protect and help their abusers because of parental duty or a general feeling of responsibility (Vrantsidis et al., 2016). In these circumstances, interventions need to be negotiated with the older person and victims need to be aware that seeking help will not automatically result in harm to them, the perpetrator, or their families (Wydall \& Zerk, 2017). To achieve this, appropriate resources must be provided, such as affordable housing and interventions not only for the victim but 
also for the perpetrator where there may be mental health or substance abuse problems (Labrum \& Solomon, 2018; Vrantsidis et al., 2016).

\section{Implications for Research}

Research evidence about help-seeking behavior among victims of elder abuse is limited by the definitional variation in terms of perpetrator relationship. The lack of specificity when defining help-seeking, with studies often merging informal and formal disclosure, limits the understanding of how these two processes relate to each other. The general crime literature finds that victims discuss their experience with others before reporting a crime to the authorities (Howitt, 2018). The merging of formal and informal disclosure across elder abuse studies negatively impacts the possibility of making targeted recommendations. Future research should examine informal and formal help seeking as a continuous and dynamic process and aim to understand the different steps taken by victims when trying to stop the abuse. For example, research could explore the idea of informal sources of help acting as a bridge to formal services by separately enquiring about the responses that victims receive from different sources and the impact that this had on further help-seeking behavior (Lafferty et al., 2013).

Identification of the different roles that informal and formal sources of help play in victims' experiences, and older people’s decisions to choose one source over the other, warrants exploration. For example, further researching the idea that formal sources may be sought in more serious cases (Mysyuk et al., 2016) could inform professionals that are likely to encounter these cases. In addition, victims’ views regarding police involvement should be investigated, given suggestions that such intervention is seen as a "last resort” (Souto et al., 2015, p. 48). Negative views regarding professionals' involvement could be related to family or generational barriers or could result from prior negative interactions, and identifying the 
reasons for such views could lead to avenues for change (Mowlam et al., 2007; Wydall \& Zerk, 2017).

Limited attention has been paid to the facilitators of help-seeking behavior, most likely due to an emphasis on the barriers faced by victims. A worrying finding is that some victims only seek help when the abuse is perceived as unbearable or they fear for their safety (Yan, 2015). Further research on help-seeking needs to be based on victims' voices and explore situations that could have facilitated earlier help seeking. Studies should aim to understand which victims are more and less likely to seek help so that interventions can be targeted accordingly (Sylaska \& Edwards, 2014).

Rates of under-reporting and barriers to help seeking might vary by type of abuse and relationship with the perpetrator and this warrants further exploration (Acierno et al., 2018; Mysyuk et al., 2016, Tamutiene et al., 2013). Understanding the different weight that these variables have on reporting could help to tailor interventions based on knowledge about abuse type and perpetrator identity. It is possible that the victims' perception of the seriousness of the abuse is mediating the relationship between abuse type and help seeking, but this has yet to be empirically tested (Burnes et al., 2017).

\section{Strengths and Limitations}

This review is limited by the inclusion criteria, which may have resulted in excluding relevant data on older people’s help-seeking that were not presented separately for victims. However, these criteria were necessary to provide a synthesis of the behaviors of older people alone. Although the goal was to be comprehensive, help-seeking could have been addressed indirectly in some studies that were eliminated. Citation searches and the review of reference lists were undertaken to limit the possibility of failing to include relevant studies. The inclusion of studies from different countries means that the illegality of elder abuse and the 
services available will vary, and this is likely to affect victims’ views regarding seeking help. Similar to the field of intimate-partner violence, the studies reviewed are limited by their reliance on cross-sectional designs and self-report (Sylaska \& Edwards, 2014), and the purposive sampling of several of the studies included limits their generalizability.

There are limitations of sample selection of included studies in representing diverse populations. For example, some included only female victims or a specific type of abuse (e.g., physical). However, most studies were inclusive of all the types of abuse commonly considered in the field of elder abuse and included female and male participants. A strength of this review is the geographic variation of studies, gathering data from 15 countries and five continents, which is unusual considering the general location bias in elder abuse research, with studies primarily conducted in the U.S. (Daly et al., 2011). This allows us to see that commonalities exist in terms of victims' help-seeking behavior in different countries and cultures, and also in people with different religious beliefs. However, it is acknowledged that culture and religion were factors that were also barriers to help-seeking and, therefore, there might be biases in sampling. Study samples were typically varied in terms of age, gender, race/ethnicity, and socioeconomic status but, generally, people who experienced cognitive difficulties were excluded from sampling and this reduced the understanding of help seeking in this population. Finally, community sampling limited knowledge of help seeking behavior for abuse occurring in institutions, which should be the focus of future research.

\section{Conclusion}

This review provided an understanding of what we know and have yet to learn regarding elder abuse victims' help-seeking behavior, and the limitations in the current available research. The studies reviewed offer a diverse and broad perspective of a phenomenon for which we have little knowledge, and which is challenging to delineate. However, the studies are limited by the lack of a standard approach to investigating help- 
seeking. Additional research is needed to address this and future studies should focus on giving a voice to victims and understanding the dynamic nature of help-seeking behavior and ways in which we can foster an environment where victims will feel safe disclosing their experiences. Practitioners and policy-makers can learn from the knowledge available and be prepared to explore barriers in their interactions with older people.

\section{References}

*indicates studies included in the review

*Acierno, R., Steedley, M., Hernandez-Tejada, M. A., Frook, G., Watkins, J., \& Muzzy, W. (2018). Relevance of perpetrator identity to reporting elder financial and emotional mistreatment. Journal of Applied Gerontology, doi: 0733464818771208

Addington, L. A. (2013). Who you calling old? Measuring “elderly” and what it means for homicide research. Homicide Studies, 17(2), 134-153. doi: $10.1177 / 1088767912461784$

*Amstadter, A. B., Cisler, J. M., McCauley, J. L., Hernandez, M. A., Muzzy, W., \& Acierno, R. (2011). Do incident and perpetrator characteristics of elder mistreatment differ by gender of the victim? Results from the National Elder Mistreatment Study. Journal of Elder Abuse \& Neglect, 23(1), 43-57. doi: 10.1080/08946566.2011.534707

Barber, J. W. (2008). The kids aren't all right: The failure of child abuse statutes as a model for elder abuse statutes. Elder Law Journal, 16(1), 107-134.

Barker, N. N., \& Himchak, M. V. (2006). Environmental issues affecting elder abuse victims in their reception of community based services. Journal of Gerontological Social Work, 48(1-2), 233-255. doi: 10.1300/J083v48n01_16 
Baxter, L., Gordon, J., \& Salmon, R. (2017). Developing an understanding of the National Trading Standards Scams Team. In A. L. Fenge, S. Lee \& K. Brown (Eds.), Safeguarding adults: Scamming and mental capacity (pp. 91-117). London: Sage.

Bergeron, L. R., \& Gray, B. (2003). Ethical dilemmas of reporting suspected elder abuse. Social Work, 48(1), 96-105. doi: 10.1093/sw/48.1.96

Booth, A., Clarke, M., Ghersi, D., Moher, D., Petticrew, M., \& Stewart, L. (2011). An international registry of systematic-review protocols. The Lancet, 377(9760), 108109. doi: 10.1016/S0140-6736(10)60903-8

*Bows, H. (2018). Practitioner views on the impacts, challenges, and barriers in supporting older survivors of sexual violence. Violence Against Women, 24(9), 1070-1090. doi: $10.1177 / 1077801217732348$

Brank, E. M., Wylie, L. E., \& Hamm, J. A. (2011). Potential for self-reporting of older adult maltreatment: An empirical examination. Elder Law Journal, 19(2), 351-384.

Braun, V., \& Clarke, V. (2006). Using thematic analysis in psychology. Qualitative Research in Psychology, 3(2), 77-101. doi: 10.1191/1478088706qp063oa

Burnes, D., Lachs, M. S., Burnette, D., \& Pillemer, K. (2017). Varying appraisals of elder mistreatment among victims: Findings from a population-based study. The Journals of Gerontology: Series B, gbx005. doi: 10.1093/geronb/gbx005

Burston, G. R. (1975). Granny-battering. British Medical Journal, 3, 592. doi: 10.1136/bmj.3.5983.592-a

Centers for Disease Control and Prevention (2018, May 18). Elder Abuse: Definitions. Retrieved March 18, 2019, from https://www.cdc.gov/violenceprevention/elderabuse/definitions.html. 
*Chokkanathan, S., Natarajan, A., \& Mohanty, J. (2014). Elder abuse and barriers to help seeking in Chennai, India: A qualitative study. Journal of Elder Abuse \& Neglect, 26(1), 60-79. doi: 10.1080/08946566.2013.782786

*Comijs, H. C., Pot, A. M., Smit, J. H., Bouter, L. M., \& Jonker, C. (1998). Elder abuse in the community: Prevalence and consequences. Journal of the American Geriatrics Society, 46(7), 885-888. doi: 10.1111/j.1532-5415.1998.tb02724.x

Cooper, C., Selwood, A., \& Livingston, G. (2008). The prevalence of elder abuse and neglect: A systematic review. Age and Ageing, 37(2), 151-160. doi: 10.1093/ageing/afm194

Critical Appraisal Skills Programme (2018). CASP Qualitative Checklist. [online] Retrieved from: https://casp-uk.net/casp-tools-checklists/ Accessed: 14 ${ }^{\text {th }}$ September 2018.

Daly, J. M., Merchant, M. L., \& Jogerst, G. J. (2011). Elder abuse research: A systematic review. Journal of Elder Abuse \& Neglect, 23(4), 348-365. doi: 10.1080/08946566.2011.608048

Dyer, C., Connoly, M., \& McFeeley, P. (2003). The clinical and medical forensics of elder abuse and neglect. In R. Bonnie \& R. Wallace (Eds.), Elder Abuse: Abuse, neglect, and exploitation in an aging America (pp.339-381). Washington DC: National Academy Press.

Dow, B., Gaffy, E., \& Hwang, K. (2018). Elder Abuse Community Action Plan for Victoria. National Ageing Research Institute. Retrieved from: http://apo.org.au/system/files/132771/apo-nid132771-591571.pdf

Elo, S., \& Kyngäs, H. (2008). The qualitative content analysis process. Journal of Advanced Nursing, 62(1), 107-115. doi: 10.1111/j.1365-2648.2007.04569.x

Enguidanos, S. M., Deliema, M., Aguilar, I., Lambrinos, J., \& Wilber, K. H. (2014). Multicultural voices: Attitudes of older adults in the United States of America about 
elder mistreatment. Ageing \& Society, 34(5), 877-903. doi: $10.1017 / \mathrm{s} 0144686 \times 12001389$

Erlingsson, C. L. (2007). Searching for elder abuse: A systematic review of database citations. Journal of Elder Abuse \& Neglect, 19(3-4), 59-78. doi: 10.1300/J084v19n03_04

Gibson, S. C. (2013). Understanding underreporting of elder financial abuse: Can data support the assumptions? (Doctoral dissertation, University of Colorado at Colorado Springs, Colorado Springs, CO). Retrieved from http://digitool.library.colostate.edu/exlibris/dtl/d3_1/apache_media/L2V4bGlicmlzL2 R0bC9kM18xL2FwYWNoZV9tZWRpYS8yMDM5MTQ=.pdf

*Gil, A. P., Santos, A. J., \& Kislaya, I. (2017). Self-reporting by older adults as victims of violence in Portugal: The remaining taboo issue. In M. Husso, T. Virkki, M. Notko, H. Hirvonen \& J. Eilola (Eds.), Interpersonal violence: Differences and connections (pp. 170-184). New York, NY: Routledge.

Heisler, C. J. (2017). Moving forward: Recommendations for advancing late-life polyvictimization practice, policy, and research. Journal of Elder Abuse \& Neglect, 29(5), 351-363. doi: 10.1080/08946566.2017.1388013

Howitt, D. (2018). Introduction to forensic and criminal psychology (6 $6^{\text {th }}$ edition). Harlow: Pearson Education.

Jackson, S. L. (2016). All elder abuse perpetrators are not alike: The heterogeneity of elder abuse perpetrators and implications for intervention. International Journal of Offender Therapy and Comparative Criminology, 60(3), 265-285. doi: $10.1177 / 0306624 X 14554063$ 
*Jackson, S. L., \& Hafemeister, T. L. (2015). The impact of relationship dynamics on the detection and reporting of elder abuse occurring in domestic settings. Journal of Elder Abuse \& Neglect, 27(2), 121-145. doi: 10.1080/08946566.2015.1008085

Killick, C., \& Taylor, B. J. (2009). Professional decision making on elder abuse: Systematic narrative review. Journal of Elder Abuse \& Neglect, 21(3), 211-238. doi: $10.1080 / 08946560902997421$

Killick, C., Taylor, B. J., Begley, E., Anand, J. C., \& O'Brien, M. (2015). Older people's conceptualization of abuse: A systematic review. Journal of Elder Abuse \& Neglect, 27(2), 100-120. doi: 10.1080/08946566.2014.997374

Krug, E. G., Dahlberg, L. L., Mercy, J. A., Zwi, A. B., \& Lozano, R. (Eds). (2002). World report on violence and health. Geneva: World Health Organization. Retrieved from: http://www.who.int/violence_injury_prevention/violence/world_report/en/full_en.pdf

Labrum, T., \& Solomon, P. L. (2018). Elder mistreatment perpetrators with substance abuse and/or mental health conditions: Results from the National Elder Mistreatment Study. Psychiatric Quarterly, 89(1), 117-128. doi: 10.1007/s11126-017-9513-z

Lachs, M. S., \& Pillemer, K. A. (2015). Elder abuse. New England Journal of Medicine, 373(20), 1947-1956. doi: 10.1056/NEJMra1404688

*Lafferty, A., Treacy, M. P., \& Fealy, G. (2013). The support experiences of older people who have been abused in Ireland. The Journal of Adult Protection, 15(6), 290-300. doi: 10.1108/JAP-02-2013-0007

Lee, Y. S., Moon, A., \& Gomez, C. (2014). Elder mistreatment, culture, and help-seeking: a cross-cultural comparison of older Chinese and Korean immigrants. Journal of Elder Abuse \& Neglect, 26(3), 244-269. doi: 10.1080/08946566.2013.820656

*Markovik, M., Peshevska, D. J., Sethi, D., Kisman, M., \& Serafimovska, E. (2014). Community survey of elder maltreatment: A report from the former Yugoslav 
Republic of Macedonia. WHO Regional Office for Europe. Retrieved from: http://www.who.int/iris/handle/10665/144072

Moher, D., Liberati, A., Tetzlaff, J., \& Altman, D. G. (2009). Preferred reporting items for systematic reviews and meta-analyses: the PRISMA statement. Annals of Internal Medicine, 151(4), 264-269.

*Mowlam, A., Tennant, R., Dixon, J., \& McCreadie, C. (2007). UK study of abuse and neglect of older people: Qualitative findings. London: King’s College London and the National Centre for Social Research.

*Mysyuk, Y., Westendorp, R. G., \& Lindenberg, J. (2016). Older persons’ definitions and explanations of elder abuse in the Netherlands. Journal of Elder Abuse \& Neglect, 28(2), 95-113. doi: 10.1080/08946566.2015.1136580

National Institutes of Health (2016). Quality assessment tool for observational cohort and cross-sectional studies. Retrieved from: https://www.nhlbi.nih.gov/healthtopics/study-quality-assessment-tools. Accessed $14^{\text {th }}$ September 2018.

*Naughton, C., Drennan, J., Lyons, I., \& Lafferty, A. (2013). The relationship between older people's awareness of the term elder abuse and actual experiences of elder abuse. International Psychogeriatrics, 25(8), 1257-1266. doi: 10.1017/S1041610213000513

*O'Keeffe, M., Hills, A., Doyle, M., McCreadie, C., Scholes, S., Constantine, R., ... \& Erens, B. (2007). UK study of abuse and neglect of older people: Prevalence survey report. London: National Center for Social Research.

Pillemer, K., Burnes, D., Riffin, C., \& Lachs, M. S. (2016). Elder abuse: global situation, risk factors, and prevention strategies. The Gerontologist, 56(Suppl_2), S194-S205.doi: 10.1093/geront/gnw004 
*Ribot, V. C., Rousseaux, E., García, T. C., Arteaga, E., Ramos, M. E., \& Alfonso, M. (2015). Psychological the most common elder abuse in a Havana neighborhood. MEDICC review, 17(2), 39-43.

*Souto, R. Q., Merighi, M. A. B., Guruge, S., \& Jesus, M. C. P. (2015). Older Brazilian women’s experience of psychological domestic violence: A social phenomenological study. International Journal for Equity in health, 14(1), 44-50. doi: 10.1186/s12939015-0173-z

Spencer, C. (2009). Environmental scan and critical analysis of elder abuse screening, assessment and intervention tools for Canadian health care providers. Public Health Agency of Canada.

Storey, J. E., \& Perka, M. R. (2018). Reaching out for help: Recommendations for practice based on an in-depth analysis of an elder abuse intervention programme. The British Journal of Social Work, 48(4), 1052-1070. doi: 10.1093/bjsw/bcy039

Sylaska, K. M., \& Edwards, K. M. (2014). Disclosure of intimate partner violence to informal social support network members: A review of the literature. Trauma, Violence, \& Abuse, 15(1), 3-21. doi: 10.1177/1524838013496335

*Tamutiene, I., De Donder, L., Penhale, B., Lang, G., Ferreira-Alves, J., \& Luoma, M. L. (2013). Help seeking behaviour of abused older women (Cases of Austria, Belgium, Finland, Lithuania and Portugal). Filosifija Sociologija., 24(4), 217-225.

United Nations (2017). World population ageing 2017 highlights. ST/ESA/SER.A/397. New York: United Nations. Retrieved from https://www.un.org/en/development/desa/population/publications/pdf/ageing/WPA20 17_Highlights.pdf 
*Vrantsidis, F., Dow, B., Joosten, M., Walmsley, M., \& Blakey, J. (2016). The older person’s experience: Outcomes of interventions into elder abuse. Melbourne, National Ageing Research Institute and Seniors Rights Victoria.

World Health Organization. (2002). Missing voices: Views of older persons on elder abuse (No. WHO/NMH/VIP/02.1). Geneva: World Health Organization.

World Health Organization (2018, June 8). Elder Abuse. Retrieved March 18, 2019, from https://www.who.int/en/news-room/fact-sheets/detail/elder-abuse.

*Wydall, S., \& Zerk, R. (2017). Domestic abuse and older people: Factors influencing helpseeking. The Journal of Adult Protection, 19(5), 247-260. doi: 10.1108/JAP-03-20170010

*Yan, E. (2015). Elder abuse and help-seeking behavior in elderly Chinese. Journal of Interpersonal Violence, 30(15), 2683-2708. doi: 10.1177/0886260514553628

Yunus, R. M., Hairi, N. N., \& Choo, W. Y. (2017). Consequences of elder abuse and neglect: A systematic review of observational studies. Trauma, Violence, \& Abuse, doi: 1524838017692798. 
Table 1

Quality Assessment of Quantitative Studies

\begin{tabular}{|c|c|c|c|c|c|c|c|c|c|}
\hline Reference & $\begin{array}{l}\text { Research } \\
\text { question }\end{array}$ & $\begin{array}{l}\text { Study } \\
\text { population }\end{array}$ & $\begin{array}{l}\text { Participation } \\
\text { rate }\end{array}$ & $\begin{array}{l}\text { Participants } \\
\text { selection }\end{array}$ & $\begin{array}{l}\text { Sample } \\
\text { size }\end{array}$ & $\begin{array}{l}\text { Exposure } \\
\text { variation }\end{array}$ & $\begin{array}{l}\text { Exposure } \\
\text { measurement }\end{array}$ & $\begin{array}{l}\text { Outcome } \\
\text { measurement }\end{array}$ & Confounds \\
\hline $\begin{array}{l}\text { Acierno et al. } \\
\text { (2018) }\end{array}$ & $\mathrm{Y}$ & $\mathrm{Y}$ & $\mathrm{Y}$ & $\mathrm{Y}$ & $\mathrm{N}$ & NA & Y & Y & $\mathrm{N}$ \\
\hline $\begin{array}{l}\text { Amstadter et } \\
\text { al. (2011) }\end{array}$ & Y & CD & Y & Y & $\mathrm{N}$ & NA & Y & Y & NA \\
\hline $\begin{array}{l}\text { Comijs et al. } \\
\text { (1998) }\end{array}$ & Y & Y & Y & Y & $\mathrm{N}$ & NA & Y & $\mathrm{N}$ & NA \\
\hline $\begin{array}{l}\text { Gil et al. } \\
\text { (2017) }\end{array}$ & Y & $\mathrm{Y}$ & Y & Y & $\mathrm{N}$ & NA & $\mathrm{Y}$ & Y & $\mathrm{N}$ \\
\hline $\begin{array}{l}\text { Markovik et } \\
\text { al. (2014) }\end{array}$ & Y & $\mathrm{Y}$ & NR & CD & $\mathrm{N}$ & $\mathrm{Y}$ & CD & CD & NA \\
\hline $\begin{array}{l}\text { Naughton et } \\
\text { al. (2013) }\end{array}$ & Y & Y & Y & Y & $\mathrm{N}$ & Y & Y & Y & CD \\
\hline $\begin{array}{l}\text { O’Keeffe et } \\
\text { al. (2007) }\end{array}$ & Y & $\mathrm{Y}$ & Y & Y & $\mathrm{N}$ & NA & Y & Y & NA \\
\hline $\begin{array}{l}\text { Ribot et al. } \\
\text { (2015) }\end{array}$ & Y & $\mathrm{N}$ & Y & Y & $\mathrm{N}$ & NA & $\mathrm{N}$ & $\mathrm{N}$ & NA \\
\hline $\begin{array}{l}\text { Tamutiene et } \\
\text { al. (2013) }\end{array}$ & Y & $\mathrm{Y}$ & NR & $\mathrm{Y}$ & $\mathrm{N}$ & $\mathrm{Y}$ & $\mathrm{Y}$ & Y & $\mathrm{N}$ \\
\hline
\end{tabular}

Note. $\mathrm{Y}=$ yes; $\mathrm{N}=$ no; $\mathrm{CD}=$ cannot determine; $\mathrm{NR}$ : not reported; $\mathrm{NA}$ : not applicable.

Adapted from the NIH tool for cohort, observational, and cross-sectional studies (National Institutes of Health, 2016). 
Table 2

Quality Assessment of Qualitative Studies and Mixed Methodology Studies

\begin{tabular}{|c|c|c|c|c|c|c|c|c|c|c|}
\hline Reference & $\begin{array}{l}\text { Research } \\
\text { aims }\end{array}$ & $\begin{array}{l}\text { Qualitative } \\
\text { methodology }\end{array}$ & $\begin{array}{l}\text { Study } \\
\text { design }\end{array}$ & $\begin{array}{l}\text { Recruitment } \\
\text { strategy }\end{array}$ & $\begin{array}{l}\text { Data } \\
\text { collection }\end{array}$ & $\begin{array}{l}\text { Relationship } \\
\text { researcher } \\
\text { participants }\end{array}$ & $\begin{array}{l}\text { Ethical } \\
\text { issues }\end{array}$ & $\begin{array}{l}\text { Rigorous } \\
\text { data } \\
\text { analysis } \\
\end{array}$ & $\begin{array}{l}\text { Findings } \\
\text { clear } \\
\text { statement } \\
\end{array}$ & $\begin{array}{l}\text { Value of } \\
\text { research }\end{array}$ \\
\hline Bows (2018) & $\mathrm{Y}$ & $\mathrm{Y}$ & $\mathrm{Y}$ & $\mathrm{N}$ & $\mathrm{Y}$ & $\mathrm{N}$ & $\mathrm{Y}$ & $\mathrm{Y}$ & $\mathrm{Y}$ & $\mathrm{Y}$ \\
\hline $\begin{array}{l}\text { Jackson \& } \\
\text { Hafemeister } \\
\text { (2015) }\end{array}$ & $\mathrm{Y}$ & $\mathrm{Y}$ & $\mathrm{N}$ & $\mathrm{Y}$ & $\mathrm{Y}$ & $\mathrm{Y}$ & $\mathrm{Y}$ & $\mathrm{CT}$ & $\mathrm{Y}$ & $\mathrm{Y}$ \\
\hline $\begin{array}{l}\text { Lafferty et al. } \\
\text { (2013) }\end{array}$ & $\mathrm{Y}$ & $\mathrm{Y}$ & $\mathrm{Y}$ & $\mathrm{Y}$ & $\mathrm{Y}$ & $\mathrm{Y}$ & $\mathrm{Y}$ & $\mathrm{Y}$ & $\mathrm{Y}$ & $\mathrm{Y}$ \\
\hline $\begin{array}{l}\text { Mowlam et al. } \\
(2007)\end{array}$ & $\mathrm{Y}$ & $\mathrm{Y}$ & $\mathrm{Y}$ & $\mathrm{Y}$ & $\mathrm{Y}$ & $\mathrm{Y}$ & $\mathrm{Y}$ & $\mathrm{Y}$ & $\mathrm{Y}$ & $\mathrm{Y}$ \\
\hline $\begin{array}{l}\text { Mysyuk et al. } \\
\text { (2016) }\end{array}$ & $\mathrm{Y}$ & $\mathrm{Y}$ & $\mathrm{Y}$ & $\mathrm{Y}$ & $\mathrm{Y}$ & $\mathrm{Y}$ & $\mathrm{Y}$ & $\mathrm{Y}$ & $\mathrm{Y}$ & $\mathrm{Y}$ \\
\hline $\begin{array}{l}\text { Souto et al. } \\
(2015)\end{array}$ & $\mathrm{Y}$ & $\mathrm{Y}$ & $\mathrm{Y}$ & $\mathrm{N}$ & $\mathrm{Y}$ & $\mathrm{Y}$ & $\mathrm{Y}$ & $\mathrm{Y}$ & $\mathrm{Y}$ & $\mathrm{Y}$ \\
\hline $\begin{array}{l}\text { Wydall \& Zerk } \\
\text { (2017) }\end{array}$ & $\mathrm{Y}$ & $\mathrm{Y}$ & $\mathrm{Y}$ & $\mathrm{Y}$ & $\mathrm{Y}$ & $\mathrm{N}$ & $\mathrm{Y}$ & $\mathrm{Y}$ & $\mathrm{Y}$ & $\mathrm{Y}$ \\
\hline Yan (2015) & $\mathrm{Y}$ & $\mathrm{Y}$ & $\mathrm{N}$ & $\mathrm{Y}$ & $\mathrm{Y}$ & $\mathrm{N}$ & $\mathrm{Y}$ & $\mathrm{Y}$ & $\mathrm{Y}$ & $\mathrm{Y}$ \\
\hline
\end{tabular}

Note. $\mathrm{Y}=$ yes; $\mathrm{N}=$ no; $\mathrm{CT}=$ cannot tell.

Based on the Critical Appraisal Skills Program (CASP, 2018) 
Table 3

Description of Reviewed Studies

\begin{tabular}{|c|c|c|c|c|c|}
\hline Reference & Country & Sample & $\begin{array}{l}\text { Help-seeking } \\
\text { definition }\end{array}$ & Objective & Main findings \\
\hline $\begin{array}{l}\text { Acierno et al. } \\
(2018)\end{array}$ & US & $\begin{array}{l}131 \text { victims of } \\
\text { financial and } \\
\text { emotional abuse }\end{array}$ & $\begin{array}{l}\text { Reporting to } \\
\text { police or other } \\
\text { authority. }\end{array}$ & $\begin{array}{l}\text { To examine } \\
\text { differences in } \\
\text { reporting between } \\
\text { known and stranger } \\
\text { perpetrators. }\end{array}$ & $\begin{array}{l}\text { Barriers: did not want perpetrator to get in trouble, did not } \\
\text { want publicity, did not want others to know, afraid to look } \\
\text { foolish, feared reprisal, did not know how to report. }\end{array}$ \\
\hline $\begin{array}{l}\text { Amstadter et al. } \\
\text { (2011) }\end{array}$ & US & $\begin{array}{l}254 \text { victims of } \\
\text { emotional, physical, } \\
\text { and sexual abuse }\end{array}$ & $\begin{array}{l}\text { Reporting to } \\
\text { police or other } \\
\text { authority. }\end{array}$ & $\begin{array}{l}\text { To examine incident } \\
\text { and perpetrator } \\
\text { characteristics } \\
\text { (including reporting) } \\
\text { of EM. }\end{array}$ & $\begin{array}{l}\text { Emotional mistreatment less likely to be reported than } \\
\text { physical and sexual mistreatment. }\end{array}$ \\
\hline Bows (2018) & UK & $\begin{array}{l}23 \text { practitioners } \\
\text { working with older } \\
\text { survivors of sexual } \\
\text { violence }\end{array}$ & $\begin{array}{l}\text { Reporting, } \\
\text { disclosing or } \\
\text { accessing } \\
\text { services. }\end{array}$ & $\begin{array}{l}\text { To examine the impact } \\
\text { of age in accessing } \\
\text { support services. }\end{array}$ & $\begin{array}{l}\text { Barriers: emotional challenges, physical impairments, } \\
\text { sociocultural challenges, lack of awareness. }\end{array}$ \\
\hline $\begin{array}{l}\text { Chokkanathan } \\
\text { et al. (2014) }\end{array}$ & India & $\begin{array}{l}6 \text { victims of } \\
\text { physical abuse by } \\
\text { family members }\end{array}$ & $\begin{array}{l}\text { Seeking both } \\
\text { formal and } \\
\text { informal } \\
\text { sources of help. }\end{array}$ & $\begin{array}{l}\text { To understand the } \\
\text { barriers that prevent } \\
\text { help-seeking. }\end{array}$ & $\begin{array}{l}\text { Barriers: service-related, religious, family-related, } \\
\text { perpetrators' threats, individual. }\end{array}$ \\
\hline $\begin{array}{l}\text { Comijs et al. } \\
\text { (1998) }\end{array}$ & Netherlands & $\begin{array}{l}99 \text { victims of verbal, } \\
\text { physical or financial } \\
\text { aggression }\end{array}$ & $\begin{array}{l}\text { Taking action to } \\
\text { prevent abuse } \\
\text { reoccurrence. }\end{array}$ & $\begin{array}{l}\text { To understand the } \\
\text { reasons for and } \\
\text { consequences of } \\
\text { abuse. }\end{array}$ & $\begin{array}{l}\text { Sources of help: } 13.3 \% \text { asked relatives/friends; } 17.8 \% \\
\text { asked professionals. } \\
\text { Outcomes: } 28.8 \% \text { actions successful (diminishing abuse); } \\
46.6 \% \text { abuse never happened again; } 24.4 \% \text { unsuccessful }\end{array}$ \\
\hline Gil et al. (2017) & Portugal & 133 EA victims & $\begin{array}{l}\text { Disclosing the } \\
\text { incident to an }\end{array}$ & $\begin{array}{l}\text { To understand help- } \\
\text { seeking behavior rates, }\end{array}$ & $\begin{array}{l}\text { 35.5\% sought help (police forces, informal social network, } \\
\text { other professionals). }\end{array}$ \\
\hline
\end{tabular}


Jackson \&
Hafemeister

\section{Lafferty et al. Ireland}

Markovik et al. Macedonia (2014)

Mowlam et al. UK

Mysyuk et al. Netherlands (2016)

Naughton et al. Ireland (2013)
71 APS workers, 55 Reporting victims of PFE,

HFE, and neglect, 32 third-party adults

9 EA victims support experiences of

307 EA victims $\quad$ Reporting

36 EA victims + 3 Taking action. relatives

17 EA victims

120 EA victims official agency or talking about it with a known person.

\section{(formally to} some authority).

To capture the circumstances under which EA is detected and reported; and the temporal relationship

between both processes.

Help-seeking (unspecified)

To examine the abused older people. (unspecified)

To explore the phenomenon of EM.

Informal and formal helpseeking.

sources, and barriers to seeking help.

To explore mechanisms and barriers to reporting.

To understand the perceptions and experiences of victims.

Disclosure to anybody. relationship between
Barriers: incident too trivial, importance of family, fear of reprisal/being left alone/institutionalized, financial dependence on perpetrator, shame.

Barriers: long-standing victim-perpetrator relationship, social isolation, difficulty labeling behavior as abuse, desire to protect perpetrator.

Facilitators: lack of emotional attachment, feelings of betrayal, ongoing positive relationship with professional, fear for personal safety.

Barriers: unawareness of abuse or services, lack of confidence, embarrassment, frightened of others knowing, accessibility issues.

Sources: variety of formal and informal sources.

Unreported in $77.3 \%$ of cases. Psychological abuse and neglect least likely to be reported.

Barriers: individual, understanding of role and remit of agencies, concern about consequences.

Facilitators: fear for safety, encouragement from others.

Barriers: hopelessness, self-blame, afraid of consequences, shame, perpetrator dependency.

Facilitators: abuse reached unbearable point.

Awareness not associated with help-seeking

Help sought in $45 \%$ of cases (family members, police,

EA awareness and help-seeking behavior. friend/neighbor, health professionals). 
O’Keeffe et al. UK (2007)

$\begin{aligned} & \text { Ribot et al. } \\ & \text { (2015) }\end{aligned}$
$\begin{aligned} & \text { Souto et al. } \\ & (2015)\end{aligned}$

Tamutiene et al. Austria, (2013) Belgium, Finland, Lithuania, Portugal

Vrantsidis et al. Australia (2016)

\section{Wydall \& Zerk UK} (2017)

Yan (2015)

\section{China}

54 EA victims

88 EA victims

11 female victims of psychological abuse by relatives

457 EA female victims

8 EA victims

5 practitioners

40 EA victims
Reporting (unspecified)

Help-seeking (unspecified)

\section{Attempts to change their current} situation.

Talk about or report most serious incident.

To generally act.

\section{Accessing services.}

Disclosure to anybody.
To describe EM in the UK.

\section{To characterize}

victims' help-seeking

behavior.

To understand psychological

domestic violence.

To examine the determinants of helpseeking behavior.

To understand the older person's experience of abuse.

To explore perceptions of barriers to help-seeking.

To explore factors associated with helpseeking.
Action taken in $70 \%$ of cases (family member/friend, health professional, social worker, other professionals).

Barriers: shame, fear of retaliation or worsening abuse, lack of knowledge about organizations.

Sources: most often a relative.

Barriers: wanting to remain in their homes, protection of abuser.

Sources: family members, police, neighbors.

Barriers: incident too trivial, lack of trust in others' ability to help, not wanting to involve anybody, not wanting perpetrator to be imprisoned, feelings of shame/guilt, fear of not being believed/retaliation.

Facilitators: higher intensity and density of abuse.

Barriers: ambivalence, parental love and duty, concerns about the perpetrator.

Facilitators: feeling supported, fear for their safety.

Barriers: socio-cultural, negative stereotypes about services, desire to remain in their communities.

Barriers: culture, belief in fate, lack of knowledge about EA, lack of an effective support network. Facilitators: seriousness of abuse, fear for safety. 
Table 4

Critical Findings

- Research to date indicates that elder abuse victims face multiple barriers when seeking help. Barriers include fear of consequences for self and the perpetrator, individual feelings and external circumstances, knowledge about services, family barriers, the characteristics of their social networks, the perception of the abuse, and cultural, generational or religious barriers.

- Some elder abuse victims only seek help when the abuse is perceived as unbearable or they fear for their safety.

- When elder abuse victims seek help, they do so from a variety of formal and informal sources.

- Rates of under-reporting and barriers to help-seeking may vary by type of abuse and relationship with the perpetrator.

- There is a dearth of research about help-seeking facilitators, the characteristics of victims most likely to seek help, and the responses that elder abuse victims encounter when they seek help.

- The evidence regarding help-seeking behavior among victims of elder abuse is limited by the lack of specificity when framing helpseeking, which does not distinguish between informal and formal disclosure, and how these two processes relate to each other.

- The understanding of help-seeking in this context is further complicated by the definitional variation of elder abuse in terms of perpetrator relationship. 
Table 5

Implications for Practice, Policy, and Research

$\begin{array}{lll}\text { Implications for practice } & \text { Implications for policy } & \text { Implications for research }\end{array}$

- Elder abuse awareness campaigns should aim to reach older people who may be both more vulnerable to abuse and more unlikely to seek help due to isolation, by understanding the means by which they are more likely to seek information.

- Increased awareness of elder abuse among professionals could enhance response to victim disclosure in a way that is likely to foster further helpseeking behavior.

- Elder abuse awareness training for professionals could usefully include engagement with the range of barriers to reporting abuse, in order to support opportunities for victim disclosure. Special sensitivity may be required when perpetrators are family members.
- Mandatory reporting policies should not only consider the detection of signs of abuse, but also knowledge of the reasons why, or the situations in which, victims might attempt to hide the abuse.

- Policy makers should integrate victims' voices and perspectives into their policies, and interventions should be individualized to victim needs and barriers to engagement.

- In cases of victimization by family members, victims need to know that reporting of abuse will not result in harm to self, the perpetrator, or their family.
- Future research should examine helpseeking as a dynamic and ongoing process and aim to understand the different steps that victims undertake when trying to stop the abuse.

- Future research should investigate formal and informal responses to victims' disclosure and their impact on further help-seeking behavior.

- Future research should focus on understanding the facilitators of helpseeking behavior and further investigate the influence of variables such as abuse type and seriousness, and perpetrator relationship. 
Figure 1. Search process
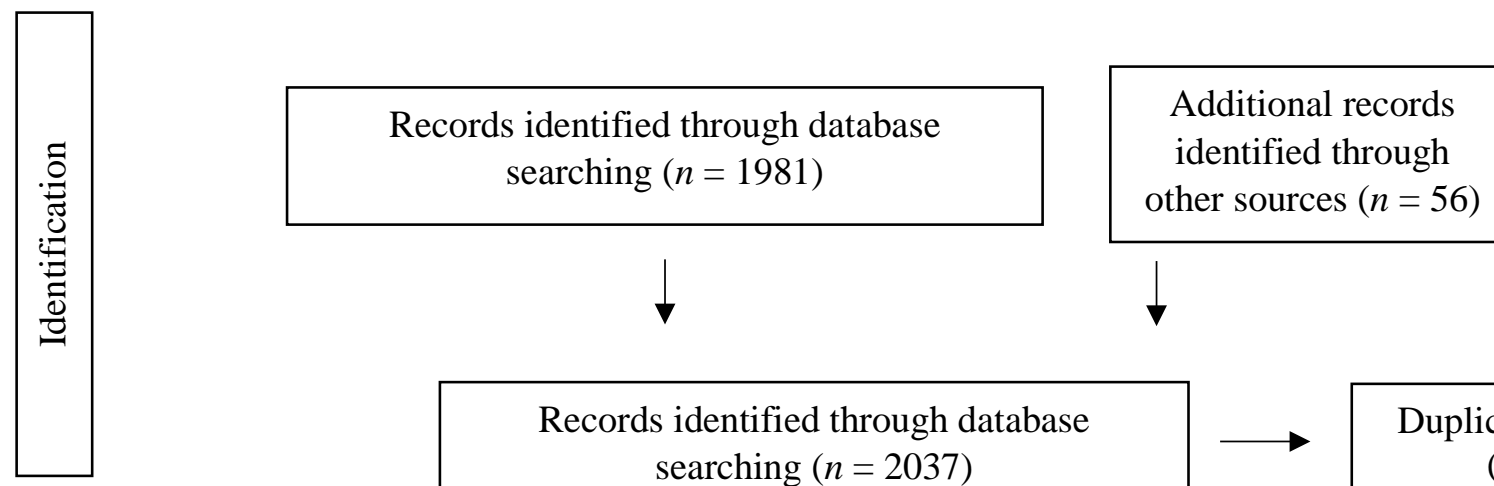

Additional records identified through other sources $(n=56)$

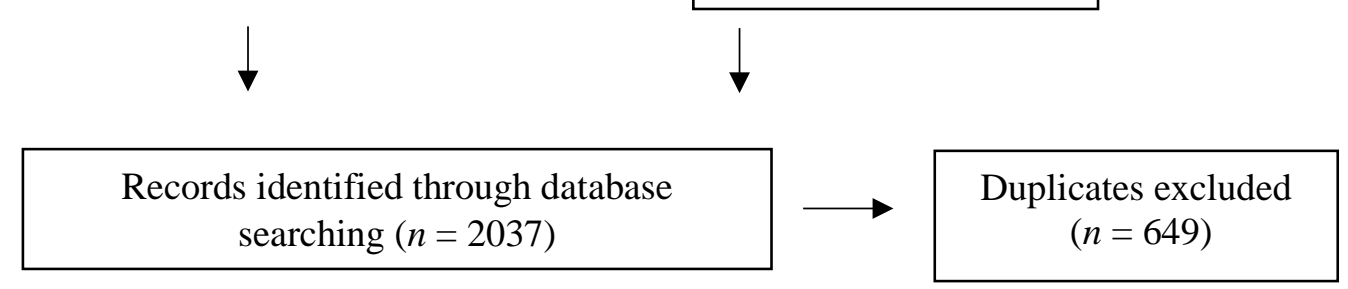

Records screened for relevance (title and abstract) after duplicates removed $(n=$ 1388)
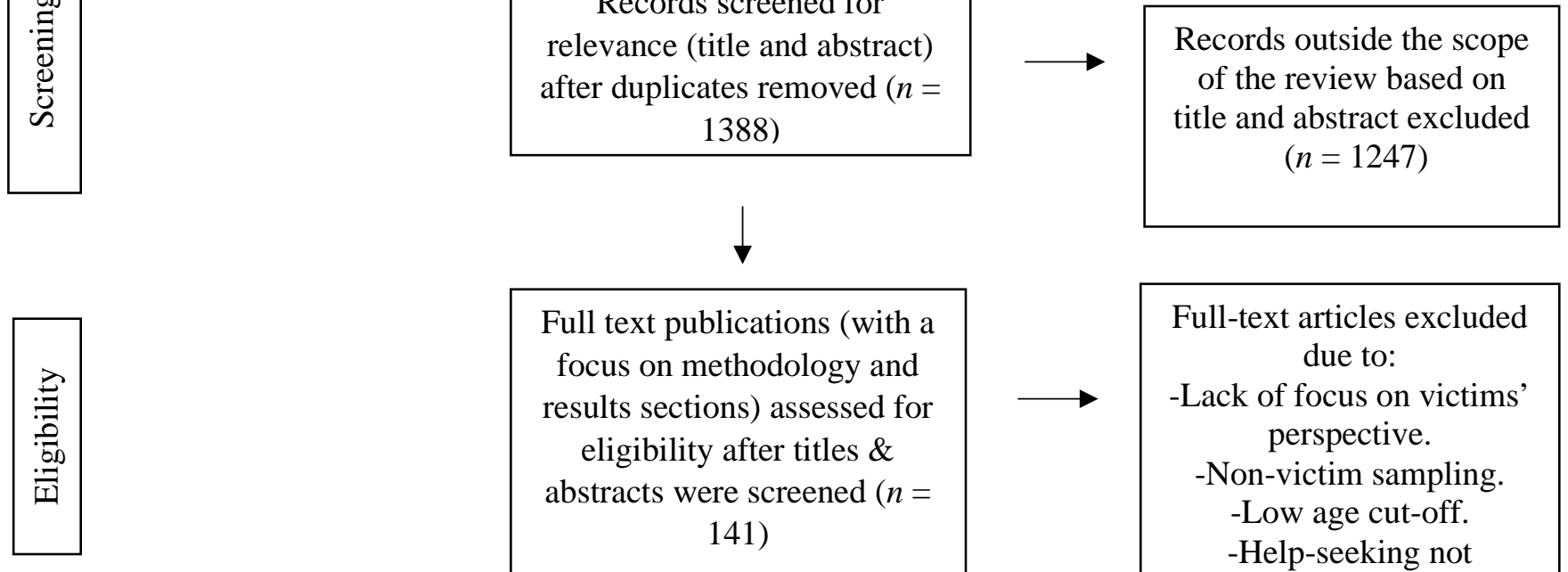

Full text publications (with a focus on methodology and results sections) assessed for eligibility after titles \& abstracts were screened $(n=$ 141)

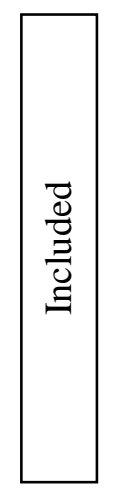

Additional references identified by a manual examination of the reference lists of articles retrieved and using Google Scholar citation tools $(n=2)$

Total articles included for review $(n=19)$

Adapted from: Moher D, Liberati A, Tetzlaff J, Altman DG, The PRISMA Group (2009). Preferred Reporting Items for Systematic Reviews and MetaAnalyses: The PRISMA Statement. PLoS Med 6(7): e1000097. doi:10.1371/journal.pmed1000097 